\title{
Pattern degradation, discrimination difficulty, and quantified stimulus attributes'
}

\author{
D. R. BROWN AND JOHN S. LoSASSO
} PURDUE UNIVERSITY

Diffusion and brightness contrast were varied to degrade random polygons. Latency to discriminate five-choice oddity problems was a function of noise conditions and was linearly related to measures of compactness, jaggedness, and rotation under noisy viewing conditions.

If noise is defined as any condition which serves to degrade a visual display, most relevant research has been limited to demonstrating how much noise can be introduced before performance is disrupted or has been directed toward methods of minimizing the effects of noise. Since the processing of information in a visual display is a function of both the display characteristics and the conditions of viewing, this interaction would appear to be an interesting focus for research. Crook (1957), for instance, has studied discrimination under noisy conditions for patterns varying in complexity. Rappaport (1957) and others (Adams et al, 1954) have found differential noise effects for patterns varying in redundancy. This study was designed to study further the relation between noise effects and quantified pattern characteristics.

\section{Patterns and Problems}

Forty 12-sided random polygons generated by Method I of Attneave \& Arnoult (1956) and described in detail by Brown \& Owen (1967) were used to construct 20 six choice oddity problems. Problems were constructed by randomly pairing two patterns, randomly designating one the "correct" pattern, and duplicating the incorrect pattern five times. The position of the correct pattern was randomly determined with the restriction that each of the six positions be used three or four times. Problems were photographed as $35 \mathrm{~mm}$ slides.

The noise conditions, diffusion and brightness contrast, were varied at three levels each. Diffusion was selected because it transforms the contour of shape; brightness contrast does not. The diffusion conditions were created by photographing problems in focus at $2.5 \mathrm{ft}$ and focused at 1.75 and $1.0 \mathrm{ft}$ (with correct focus at $2.5 \mathrm{ft}$ ) with a compensating depth of field. Brightness was varied in three steps by presenting problems without a filter, and with either a 1.5 or $3.0 \mathrm{log}$ neutral density filter in front of the projector lens.

Method

Each of 24 students, 11 male and 13 female, was presented with the 180 problems defined by 20 problems viewed under the nine conditions. A latin square arrangement controlled sequence and order for the nine treatment conditions, and problem sequences were randomized within conditions.

When $E$ presented a ready light, $S$ initiated each trial by releasing a "start" button which opened a shutter on the random access projector, back-projected the problem on a viewing booth, and started a msec timer. $S$ responded by depressing one of six illuminated buttons, spatially arranged to be congruent with problem patterns, to select the odd pattern. For correct choices, the problem was extinguished and the timer stopped. For incorrect choices, the display remained, the error was counted, and the timer continued until a correct response was made.

Ss were instructed to respond as rapidly as possible without errors. Testing was carried out in a dimly lighted room in $60 \mathrm{~min}$ sessions, and was preceded by 16 practice problems.

\section{Resulis and Discussion}

An analysis of variance of latencies yielded significant main effects for diffusion, brightness, and their interaction $(p<.01)$. When the interaction is plotted, as in Fig. 1, it is clear that these effects are largely a function of the degrading effects of the high diffusion condition and the increased effect of combining low contrast with high diffusion. Comparisons among condition means using the Newman-

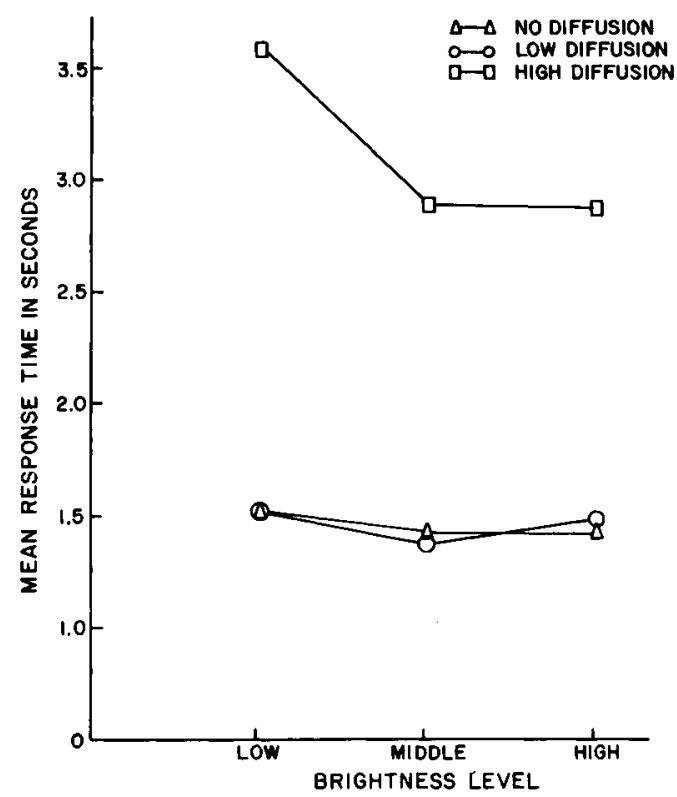

Fig. 1. Mean response latency for each condition. 
Keuls procedure (Winer, 1962) showed that this latter condition differed from all other conditions, and all high diffusion means differed from all low and no diffusion means $(p<.01)$. No other differences were significant. These results support the conclusion that pattern degradation is effective if it modifies contour, the information conveying aspect of patterns such as these.

Correlation analyses were used to relate quantified pattern characteristics to performance. Eighty measures $^{2}$ of each pattern were reduced to a small number of linearly independent factor scores measuring primarily compactness, jaggedness, y-axis areal asymmetry, x-axis asymmetry, and rotation. Herein, one measure was selected from the 80 to assess each of these pattern attributes. These were: (1) perimeter length, (2) second moment of interior angles, (3) third moment of $y$ coordinates, (4) third moment of $\mathbf{x}$ coordinates, and (5) rotation of maximum complementary radial pair, respectively. Linear correlations were computed among latencles for the nine treatments across the 20 problems. In addition, absolute intraproblem differences for each of the five pattern measures were correlated with latency in each treatment condition.

An interesting pattern emerged from the intercorrelation among latency scores which strongly supports the analysis on means. The correlations among conditions involving the highest diffusion level ranged from .70 to .95; among conditions not involving this condition they ranged between .68 and .92 ; but between conditions of high diffusion and other conditions, the maximum correlation was $\mathbf{- . 2 2}$. Clearly, performance was clustered into two sets of conditions even when examined across individual problems. Consequently, the regression of latency upon pattern characteristics was examined only for the two extreme conditions of high contrast-no diffusion and low contrast-high diffusion.

The standard score linear regression equations predicting latency in these two conditions were:

(1) $\mathrm{L}_{1}=-.02 \mathrm{X}_{1}-.52 \mathrm{X}_{2}+.18 \mathrm{X}_{3}+.05 \mathrm{X}_{4}+.33 \mathrm{X}_{5}$

(2) $\mathrm{L}_{2}=.52 \mathrm{X}_{1}+.24 \mathrm{X}_{2}-.14 \mathrm{X}_{3}+.06 \mathrm{X}_{4}+.38 \mathrm{X}_{5}$

in which $\mathrm{L}_{1}$ and $\mathrm{L}_{2}$ are predicted latencies for the respective conditions and the $X_{i}$ represent the five pattern measures. The squared multiple correlations were .32 and .55 for the two equations, respectively, and the second is significantly different from zero $(p<.05)$. These equations are interesting in two regards. The relative magnitude of weights in Eq. (2) supports previous studies wherein measures similar to $\mathrm{X}_{1}$ and $\mathrm{x}_{2}$ predict judged complexity (Attneave, 1957; Owen \& Brown, 1966), and $X_{5}$ has been related to discrimination difficulty (Brown et al, 1962). This suggests that under noise free conditions performance is not consistently related to these pattern attributes, but under blurred conditions they are consistently used. This may be due to the relative ease of discrimination or to the fact that these measures are sensitive only to global pattern attributes which are useful when patterns are blurred but are otherwise not consistently useful.

\section{References}

ADAMS, O. S., FITTS, P. M., RAPPAPORT, M., \& WEINSTEIN, M. Relations among some measures of pattern discriminability. $J$. exp. Psychol, 1954, 48, 81-88.

ATTNEAVE, F., \& ARNOULT, M. D. The quantitative study of shape and pattern perception. Psychol. Bull, 1956, 53, 452-471.

ATTNEAVE, F. Physical determinants of the judged complexity of shapes. J. exp. Psychol, 1957, 53, 221-227.

BROWN, D. R., HITCHCOCK, L., Jr., \& MICHELS, K. M. Quantitative studies in form perception: an evaluation of the role of selected stimulus parameters in the visual discrimination performance of human subjects. Percept. mot. Skills, 1962, 14, 519-529.

BROWN, D. R., \& OWEN, D. H. The metrics of visual form: methodological dyspepsia. Psychol. Bull., 1967, 68, in press.

CROOK, M. N. Facsimile generated analogous for instrumental forms displays. In J. W. Wulfeck \& J. H. Taylor (Eds.), Form discrimination as related to military problems. Washington: MAS-NRC Publication No. 561, 1957. Pp. 85-98.

MICHELS, K. M., \& ZUSNE, L. Metrics of visual form. Psychol. Bulh, $1965,63,74-86$.

OWEN, D. H., \& BROWN, D. R. Physical correlates of pattern perception for the visual and tactual modalities. Presented at the Amer. Psychol. Assoc., New York, September, 1966.

WINER, B. J. Statistical principles in experimental design. New York: McGraw-Hill, 1962.

\section{Notes}

1. This research was supported by Research Grant HD-00909 from the National Institute of Child Health and Human Development.

2. For detailed discussion of these measures and the quantification procedure see Brown \& Owen (1967). 